\title{
Educação superior: o desenuolvimento das capacidades e o processo de humanização
}

\author{
Higher education: the development of the capabilities and the \\ humanization process
}

\section{Educación superior: el desarrollo de las capacidades y el proceso de humanización}

\author{
Lidiane Limana Puiati Pagliarin' \\ Universidade Federal da Fronteira Sul, Professora \\ https://orcid.org/0000-0002-5390-5167 \\ Patricia Carlesso Marcelino ${ }^{2}$ \\ Universidade de Passo Fundo, Pesquisadora. \\ http://orcid.org/0000-0002-9084-1182 \\ Rosana Cristina Kohls ${ }^{3}$ \\ Universidade de Passo Fundo, Pesquisadora. \\ https://orcid.org/0000-0003-3912-0133
}

\begin{abstract}
Resumo: 0 texto tem como objetivo discutir os desafios da Educação Superior no sentido de promover uma formação humana que preserve os princípios democráticos e de cidadania. Ele apresenta uma análise reflexiva, reconstrutiva-crítica-hermenêutica, de caráter bibliográfico, a partir do pensamento de Martha Nussbaum com relação ao desenvolvimento das capacidades, em conexão com outros autores vinculados à temática da educação superior e dos processos de humanização. Compreendemos que as capacidades humanas são elementos essenciais para que se efetive o desenvolvimento humano no âmbito da educação superior, além de ressaltar a importância de um currículo universitário e escolar que contemple uma formação mais sensivel e humanizada.

Palavras-chave: Educação Superior. Capacidades. Martha Nussbaum. Humanização.
\end{abstract}

Abstract: The text aims to discuss the challenges of Higher Education in the sense of promoting a human formation that preserves democratic and citizenship principles. It presents a reflexive, reconstructivecritical-hermeneutic analysis, with a bibliographic character, from the thought of Martha Nussbaum, in relation to the development of the capabilities, in connection with other authors linked to the theme of

Doutora em Educação pela Universidade de Passo Fundo; Mestre em Educação pela Universidade Federal de Santa Maria.

Doutora e Mestre em Educação pela Universidade de Passo Fundo.

Doutora em Educação pela Universidade de Passo Fundo; Mestre em Educação pela Universidade do Contestado. 
higher education and humanization processes. It is understood that human capabilities are essential elements for the realization of the human development in the context of the higher education, in addition to emphasizing the importance of an university and a school curriculum that includes a more sensitive and humanized formation.

Keywords: Higher Education. Capabilities. Martha Nussbaum. Humanization

Resumen: El texto tiene como objetivo discutir los desafios de la Educación Superior con el fin de promover la formación humana que preserva los principios democráticos y de ciudadanía. Presenta un análisis reflexivo, reconstructivo-crítico-hermenéutico, de carácter bibliográfico, basado en el pensamiento de Martha Nussbaum sobre el desarrollo de capacidades, en conexión con otros autores vinculados al tema de la educación superior y los procesos de humanización. Se entiende que las capacidades humanas son elementos esenciales para la realización del desarrollo humano en el contexto de la educación superior, además de enfatizar la importancia de un plan de estudios universitario y escolar que incluya una formación más sensible y humanizada.

Palabras clave: Educación Superior. Capacidades. Martha Nussbaum. Humanización.

\section{INTRODUÇÃO}

A contemporaneidade em que nos inscrevemos encerra um tesouro de enormes possibilidades e expectativas, algumas das quais nos fazem sonhar com a realização de novos projetos e utopias. Segundo Barbosa (2006), no entanto, também evidenciamos problemas, desenvolvem-se condutas não solidárias, radicaliza-se a afirmação de convicções e valores discriminadores, propaga-se a intolerância, aprofundam-se as desigualdades, multiplicase a injustiça, nega-se o usufruto de direitos, cresce o separatismo urbano, formam-se comunidades do medo, aumenta o receio em relação ao estranho e convive-se mal com a diferença. 0s problemas em causa são mais sistêmicos e globais que particulares e locais. A globalização neoliberal, a crise econômica global, o estado global de guerra, o integralismo culturalista e o extremismo identitário são os seus bastidores e, em grande parte, os seus promotores.

Esposito (2017, p. 16) aponta que o corpo que experimenta de modo sempre mais intenso a indistinção entre política e vida não é mais o do indivíduo, nem o corpo soberano das nações, mas o corpo ao mesmo tempo dilacerado e unificado do mundo. Para o autor, "nunca, como hoje, os conflitos, as feridas e os medos que o afligem parecem colocar em jogo 
nada menos do que a própria vida, numa singular inversão entre o filosoficamente clássico do 'mundo da vida' e o motivo, atualíssimo, da 'vida do mundo'." Assim, Esposito (2017) defende que a reflexão não pode ocorrer de forma anacrônica das categorias modernas sob o olhar do biopoder nazista.

A educação também se insere nesse emaranhado de situações complexas e desafiadoras, as quais desestabilizam os modelos, as formas e até mesmo o sentido que se atribui à formação humana pelo viés das instituições de ensino tradicionais. Neste sentido, é recorrente a ideia de que enfrentamos uma crise no campo educacional. Nussbaum (2010) indica que essa crise está sendo gestada a longa data, mas vem passando despercebida. Essa crise, segundo ela, é de enorme gravidade e em escala mundial, resultado de uma fragilização das democracias e, como consequência, sobre as formas de viver pautadas em um modo de vida democrático.

A autora enfatiza que tal crise, a que se refere, não é a econômica que atinge o mundo desde 2008, mas, "uma crise que passa praticamente despercebida, como o câncer. Refiro-me a uma crise que, com o tempo, pode se tornar muito mais prejudicial para o futuro da democracia: a crise global na educação." (NUSSBAUM, 2010, p. 20, tradução nossa).

Dessa maneira, percebemos que há uma estreita ligação entre democracia e educação e, como consequência, em relação ao que denominamos de uma formação para a cidadania. Sendo assim, parece-nos pertinente que se estabeleçam diálogos capazes de auxiliar na busca de alternativas e quiçá algumas respostas necessárias não só para evitar o definhamento da cidadania, como também para robustecer a democracia.

A pergunta que se coloca é: Como a docência na educação superior poderá viabilizar e criar novas possibilidades de enfrentamento para uma formação humana que preserve os princípios democráticos e de cidadania?

Neste sentido, a educação institucionalizada, no quadro das políticas educativas estatais, segundo Barbosa (2006), ganha cada vez mais importância na elaboração dessa resposta. A intenção, contando com o seu poder indutor de atitudes e comportamentos, é fazer da educação uma via privilegiada de reconstrução da cidadania e da democracia num contexto de lutas e debates em torno do reconhecimento cultural e da redistribuição da riqueza.

Perspectiva-se, assim, num ambiente de crescente diferenciação cultural das sociedades e da sua inscrição em esferas globais ou mundiais, a abertura para as cidadanias emergentes, necessariamente mais plurais, mais interculturais e, também, cosmopolitas. Porém, esse "reinvestimento da educação com esses sentidos e significados" traz desafios à docência e coloca as "práticas educativas perante a obrigação de se renovar, para que possa corresponder às exigências que doravante se colocam à formação de cidadãos e de 
sujeitos políticos." Apesar desses desafios, "serão as suas ideias renovadas e atualizadas, no quadro de uma teoria de ação educativa, que poderão induzir novos modos de fazer cidadanização para a democracia, especialmente no contexto escolar." (BARBOSA, 2006, p. 10).

Dessa forma, o objetivo deste ensaio é discutir os desafios da educação superior no sentido de promover uma formação humana que preserve os princípios democráticos e de cidadania. Para isso, desenvolvemos uma análise qualitativa quanto à abordagem do problema, reconstrutiva, crítica e hermenêutica quanto ao objetivo e bibliográfica quanto aos procedimentos. A pesquisa está ancorada em autores que se vinculam com o contexto da educação superior e com a crise global, mas especialmente no conceito basilar da teoria das capacidades defendidas por Martha Nusssbaum (2010, 2012, 2015).

0 texto está organizado em duas partes: a primeira parte evidencia e discute desafios da docência na Educação Superior no contexto atual, marcado por questionamentos e dilemas quanto à formação humana. A segunda parte apresenta as capacidades humanas defendidas por Martha Nussbaum como elementos essenciais para que se efetive o desenvolvimento humano, bem como ressalta a importância da educação e de um currículo escolar e universitário amplos para essa formação humana.

\section{EDUCAÇÃO SUPERIOR: DESAFIOS DA DOCÊNCIA NO CONTEXTO DA CONTEMPORANEIDADE}

A Educação Superior e, como consequência, as instituições de ensino superior, sejam elas universidades, faculdades ou centros universitários, encontram-se inseridas nesse contexto de crise a que nos referimos anteriormente e sobre o qual nos alertava Martha Nussbaum, já há algum tempo. A complexidade do momento histórico associada a mudanças que vinham se processando de longa data na educação corrobora para que tais instituições e o ensino encontrem-se em uma situação de fragilidade, a qual podemos classificar como uma crise de autenticidade e identidade.

Segundo Kohls (2019, p. 11) se, no século passado, o presidente Kerr sugeriu que a universidade deveria se chamar multiversidade, o que diríamos frente à situação em que essas instituições se encontram hoje? Trata-se de uma instituição até certo ponto fragilizada na sua liberdade, autenticidade e autonomia, o que nos faz inferir que ainda não tivemos um "modelo autêntico" de universidade no Brasil. Primeiramente, seguiu-se o modelo europeu, depois, recebeu-se a influência norte-americana, e, atualmente, há forte influência europeia. Ao olharmos para essas instituições, percebemos que são muitos e diversos os conflitos, as angústias, os dilemas e a complexidade das situações que envolvem a Educação Superior. 
Entre os conflitos e desafios enfrentados pela área da Educação Superior, situase a questão da docência e, com ela, a questão do currículo, da didática e das metodologias apropriadas ou não para que esse nível de ensino desempenhe um papel significativo na formação humana. Com a ocorrência de um processo acelerado de transformações na sociedade, a educação passou a ser questionada e, neste sentido, precisa ser repensada. As novas configurações sociais trouxeram vários debates, dentre eles, a formação dos sujeitos: uma formação mais pragmatista e aligeirada ou uma formação integral e humana?

Desse questionamento, desdobram-se tantos outros, como, por exemplo: Qual modelo de formação tem sido desenvolvido nas universidades: Modelos que contemplem a formação humana e integral do sujeito ou modelos voltados para o desenvolvimento econômico, dotados do pragmatismo economicista? Frente aos avanços tecnológicos e aos avanços de formação na modalidade EAD (Educação a Distância), como fica a formação presencial? É possível uma formação voltada para a cidadania, a qual pressupõe a troca de conhecimentos, a dialogicidade, a interação, a mediação e a socialização, sem a presença/ atuação do professor?

Ao concordarmos que a educação é um dos elementos fundamentais na formação humana, há que se considerar, nesse processo, a importância da docência. Contraditoriamente aos discursos que enaltecem os aparatos tecnológicos e as promessas de uma possível auto formação, o professor, sua atuação, enquanto mediador e decodificador de significados, conceitos, sentidos e análise para a compreensão dos conhecimentos historicamente acumulados, parece que se reforça ao invés de enfraquecer.

No Brasil, recentemente, vivenciamos um movimento em torno da educação domiciliar ou homeschooling, uma proposta polêmica apresentada em 2015 que está gerando controvérsias. 0 referido Projeto de Lei $n^{\circ}$. 3261/2015 prevê autorização para o ensino domiciliar na educação básica e preconiza que a educação escolar possa ser dirigida pelos próprios pais ou pelos responsáveis legais, tendo apenas, como exigência legal, o cumprimento de calendário de avaliações (BRASIL, 2015). Esse fato contou com o apoio de parte da população, naquele momento.

Porém, em 2020, quando as famílias estão sendo obrigadas a ficar em suas casas e a conduzir o processo educativo dos filhos, devido à pandemia da COVID-19, não se percebe qualquer continuidade do movimento em prol da educação domiciliar, principalmente na educação básica. Ao contrário, vemos declarações em redes sociais de pais desesperados e sem saber como conduzir o processo. Já na Educação Superior, neste momento de pandemia,

0 Projeto de Lei $n^{\circ}$. 3261/2015 prevê autorização para o ensino domiciliar na educação básica e preconiza que a educação escolar possa ser dirigida pelos próprios pais ou pelos responsáveis legais, tendo apenas, como exigência legal, ○ cumprimento de calendário de avaliações. Em 11 de abril de 2019, o projeto, seguiu para a Câmara dos Deputados para apreciação, porém, até o presente momento ainda não foi votado. 
o ensino remoto tem sido adotado por algumas instituições, porém, essa estratégia tem mostrado seus limites, uma vez que vários discentes não possuem condições para participar das aulas, pois falta-lhes acesso à rede de internet e equipamentos tecnológicos.

Os debates culturais, políticos e ideológicos do nosso tempo, segundo Santos (2020), têm uma opacidade estranha que decorre da sua distância em relação ao cotidiano vivido pela grande maioria da população, os cidadãos comuns - « la gente de a pie », como dizem os latino-americanos:

\begin{abstract}
Em particular, a política, que devia ser a mediadora entre as ideologias e as necessidades e aspirações dos cidadãos, tem vindo a demitir-se dessa função. Se mantém algum resíduo de mediação, é com as necessidades e aspirações dos mercados, esse megacidadão informe e monstruoso que nunca ninguém viu nem tocou ou cheirou, um cidadão estranho que só tem direitos e nenhum dever. É como se a luz que ele projeta nos cegasse. De repente, a pandemia irrompe, a luz dos mercados empalidece, e da escuridão com que eles sempre nos ameaçam se não the prestarmos vassalagem emerge uma nova claridade. (SANTOS, 2020, p. 10).
\end{abstract}

0 autor reforça a claridade pandêmica e as aparições em que ela se materializa. 0 que ela nos permite ver e o modo como for interpretado e avaliado determinarão o futuro da civilização em que vivemos. Essas aparições, ao contrário de outras, são reais e vieram para ficar. Ele finaliza de maneira pouco animadora que:

As pandemias mostram de maneira cruel como o capitalismo neoliberal incapacitou o Estado para responder às emergências. As respostas que os Estados estão a dar à crise variam de Estado para Estado, mas nenhum pode disfarçar a sua incapacidade, a sua falta de previsibilidade em relação a emergências que têm vindo a ser anunciadas como de ocorrência próxima e muito provável. Estou certo de que nos próximos tempos esta pandemia nos dará mais lições e de que o fará sempre de forma cruel. Se seremos capazes de aprender é por agora uma questão em aberto. (SANTOS, 2020, p. 32).

Nesse mesmo contexto, as universidades e os professores universitários foram muitas vezes mal interpretados, sofrendo críticas por vezes evasivas e desconexas com a realidade. Dizem, por exemplo, que as universidades recebem muitos recursos e que não há retorno social de seu trabalho (MEC..., 2019; SOUZA, 2019).

Essa crise apontada por Santos (2020) teve desdobramentos, no caso brasileiro, tanto na educação básica quanto na educação superior. Dentre eles, citamos, como exemplo, a educação à distância implementada urgentemente a grosso modo, em plena pandemia de COVID- 19, sem uma cuidadosa organização, estruturação, formação e apoio aos docentes 
e discentes, e também, como vemos todos os dias, através das mídias sociais, em diversos contextos, uma educação remota acontecendo, muitas vezes, sem recursos financeiros e sem as mínimas condições de infraestrutura de equipamentos e de conexões de internet, extremamente necessária para a participação dos alunos nas aulas, prejudicando, assim, os processos de ensino e de aprendizagem, bem como o cumprimento da carga horária escolar.

Presenciamos também, somados a tudo isso, a desvalorização da profissão docente derivada dessa crise educacional, que também se multiplica, em ataques à ciência e aos professores-pesquisadores. No entanto, a produção de conhecimento, a pesquisa, a extensão e o ensino são pilares para o desenvolvimento de uma sociedade e objetivo dessas instituições. Hoje, pelo mesmo motivo da pandemia, os pesquisadores, as universidades e a ciência são a única esperança de que, por meio da pesquisa cientifica, encontre-se a "cura do mal".

Essas exemplificações são ilustrativas da complexidade que envolve a questão da docência e do papel do professor, assim como da educação em geral, no atual contexto histórico, transformando esses profissionais e essas instituições em "heróis e bandidos" ao mesmo tempo. Assim, tanto o conhecimento quanto os professores passam a ser ora humilhados e rechaçados, ora reconhecidos, ora descartáveis, ora necessários (KOHLS, 2019, p. 120). Expresso em outros termos, vivemos no limiar das contradições e ambiguidades. 0 certo é que, em parte, essa situação fragiliza, descaracteriza e enfraquece a identidade dos educadores e a significância da docência.

Não são somente as condições objetivas que se colocam como um desafio à docência no ensino superior, existem questões subjetivas que interferem na atual conjuntura. Entre elas, destacamos um notório tensionamento entre os saberes clássicos e a modernidade, caracterizado pelas "contradições em relação à experiência de vida e à intelectualidade em contraposição aos modernismos nostálgicos de uma ordem superficial, imediatista e que despreza a cultura e a história em nome da inovação e da mudança permanente." (KOHLS, 2019, p. 120).

Especialmente nas universidades, a condição dos docentes apresenta-se muito discrepante em relação às universidades públicas e privadas. Considere-se que as universidades privadas e ou comunitárias são aquelas localizadas no interior do país, atendendo a uma parcela da população de menor poder aquisitivo, ou seja, as piores condições de trabalho e valorização docente ocorrem justamente nas instituições que atendem a classe trabalhadora e que tem dificuldades de acesso e permanência na educação superior. Assim, configura-se essa situação:

Os professores com maior titulação e regime de tempo integral atuam nas universidades públicas e que o regime parcial ainda prevalece nas faculdades e universidades privadas. Sabe-se que o tempo integral é 
condição necessária para um trabalho de qualidade e para a garantia de condições dignas de trabalho. Ou seja, no segmento privado - o que mais cresce - é onde os docentes têm as piores condiç̃̃es de trabalho. Assim, confirma- se a visão mercadológica e um "ensino" técnico profissionalizante, que é aquele possivel de ser ministrado pelo professor horista, uma vez que, dessa forma, ele não consegue envolver-se em projetos de pesquisa e desenvolver programas de extensão. (KOHLS, 2019, p. 117-118).

Sendo assim todo o contexto contribui para uma formação que vise produzir um sujeito competitivo, capaz de se adaptar ao mercado, ao invés de questioná-lo e reinventá-lo. Disso resulta uma cultura acadêmica desvinculada das humanidades, da formação integral, do ser humano, muito antes ao contrário, essa supremacia do econômico sobre o humano tem muito mais promovido um adestramento por meio de uma "gestão das mentes" do que promovido a libertação dos indivíduos.

Partindo dessas reflexões a ideia que nos propomos desenvolver refere-se a uma docência que considere a educação na perspectiva do que indica Nussbaum (2010, p. 39, tradução nossa): "a educação não consiste na assimilação passiva de dados e conteúdos culturais, mas em colocar desafios para que o intelecto se torne ativo e competente, dotado de pensamento crítico para um mundo complexo."

Percebemos que os ideais neoliberais da adaptabilidade, do empreendedorismo e da flexibilidade estão presentes nas práticas pedagógicas e como objetivos centrais, na organização curricular da Educação Superior. Há que se atentar para isso uma vez que:

\footnotetext{
Esse pensamento é provocativo, pois sinaliza para a possibilidade de uma educação frustrada, que, ao invés de libertar, aprisiona, ao invés de emancipar, aliena, submetendo o homem a uma ordem que the é imposta com ares de modernidade. Caso queiramos contribuir para que as sociedades democráticas subsistam, é preciso colocar à mesa de debates as condições, os meios, os fins e os objetivos da formação, especialmente considerando as características de vida das novas gerações, compreendendo as reais necessidades que esse tempo histórico no qual estamos inseridos requer, para que os processos formativos tenham sentido e significado emancipador. (KOHLS, 2019, p. 26).
}

Com relação à docência que busca uma formação humanizada e humanizadora, Strieder (2002) explica que refletir a condição humana e perspectivar uma educação para o entendimento é permitir-se o direito de admirar a fantástica aventura da vida e, em particular, a aventura vivencial dos seres humanos. É desejar "ensonhar" um ser humano bem mais diverso do que a racionalidade do oeconomicus pretendem. Humanizar requer manter acesa a chama da vivência criativa, regada pela afetividade, pela sensibilidade, pelo riso, pelas lágrimas, pelo fervor da participação, pelas luzes do respeito e pelo desejo de cultivar, no 
jardim da vida, a vivência da beleza. E, na condição de "filhos da vida", reconhecer que a vida é uma aventura da criatividade e, nela, o futuro de cada qual bem como da humanidade requer construção.

Mühl (2018) enfatiza que educar em uma sociedade de risco e em um mundo fora de controle é uma tarefa hercúlea, que exige muita competência por parte da escola e de seus educadores. Neste sentido, será necessário pensarmos aproximações para educar para a sensibilidade e a humanização:

\footnotetext{
A sensibilidade, a humanização, o cuidado de si, do outro e da natureza são dispositivos poderosíssimos para quem escolher o posicionamento de fazer a diferença em seu entorno. São capacidades que podem ser mobilizadas em todos os contextos, através de atos e práticas de cuidado, de gentileza e de delicadeza, nesses tempos de barbárie, de egoísmo, de egocentrismo, de desrespeito à natureza e de exclusão social. (MARCELINO, 2019, p. 196).
}

É necessário, segundo Strieder (2002), que ocorra uma opção da humanidade para considerar preferivel o resgate das relações de confiança, de colaboração mútua e do relacionamento afetivo, sobretudo as relações conflitivas da competição. Isso exige uma virada muito grande dos seres humanos, para que esse resgate se torne desejo. Recentralizar a colaboração espontânea, como um novo elemento articulador das relações entre os humanos vivendo em sociedades complexas, clama por involuções e evoluções conceituais, mas também vivenciais.

Não será fácil a decisão de abdicar do grande "hall" das crenças que sedimentam a condição humana como que fundada no conflito da competição. Sabemos que, por serem consideradas crenças, tornam-se praticamente intocáveis. Quando o campo dos entendimentos e das significações se localiza na dimensão das crenças, sua adesão é mais profunda e, consequentemente, o desejo de removê-las terá que ser muito mais audacioso.

\footnotetext{
0 tempo na educação passa a ter outro sentido, dado que essa noção se distancia dos valores da utilidade e da praticidade próprios da visão hegemônica. Novas experiências de formação podem ocorrer nessa perspectiva, não no horizonte cronológico, mas na expectativa do tempo nas narrativas. Desfaz-se, assim, a noção de passagem de um aquém a um além (do tempo) exclusivamente, pois tais esquemas foram literalmente erodidos em prol de uma lógica poética e retórica ao mesmo tempo, e, por isso (trans) formativa. (TREVISAN, 2016, p. 269).
}

Esposito (2017) complementa que um único processo atravessa sem solução de continuidade toda a extensão do vivente - que qualquer vivente deva ser pensado na 
unidade da vida -, significa que nenhuma parte dela pode ser destruída em favor de outra: toda vida é forma de vida e toda forma - refere-se à vida. Esse não é o conteúdo e o sentido último da biopolítica. Mas é, pelo menos, seu pressuposto: se mais uma vez será renegado numa política da morte, ou afirmado numa política da vida, dependerá também do modo como o pensamento contemporâneo seguirá seus rastros.

Há, então, a preocupação com a necessidade de se pensar formas e práticas de docência, que estejam comprometidas com a humanização, no entanto, essa condição constitui-se como um desafio à Educação Superior. As buscas por elementos que possam subsidiar os educadores tanto em suas práticas pedagógicas cotidianas, quanto na estruturação dos documentos norteadores dos cursos, como os Planos Pedagógicos ou Projetos Pedagógicos, os quais podem servir de guias para que as ementas das disciplinas tenham imbricados princípios de formação humana, independente do curso e ou área do conhecimento, leva-nos a sugerir a utilização dos ensinamentos de Nussbaum que traz, como um dos elementos centrais da formação humana, as capacidades, na perspectiva de uma formação que considere a liberdade e a justiça social.

\section{CRIAR CAPACIDADES: POR UMA EDUCAÇÃO SUPERIOR PARA O DESENUOLUIMENTO HUMANO}

A filósofa norte-americana Martha Nussbaum (2010), esclarece que muitas nações, em nome do desenvolvimento econômico, têm negligenciado sobre o futuro da educação e da democracia, que, segundo ela, "está por um fio". Assim, podemos dizer que as nações, no momento de tomada de decisões e definição de objetivos e investimentos têm como base dois paradigmas: Ou amparam-se no paradigma do Desenvolvimento Humano ou no Paradigma do Desenvolvimento Econômico. A análise da conjuntura atual leva-nos à percepção que prevalece quase de forma absoluta o modelo de desenvolvimento econômico. Embora há que se admitir que o mesmo não ocorre de forma "pura" e nem com as mesmas características em todas as nações capitalistas do globo. Ou seja, mesmo nos países onde o capitalismo financeiro desenvolve-se de maneira mais radical, inclusive nesses países, encontram-se alguns elementos do modelo de desenvolvimento humano, caso contrário, toda a população desses países pereceria na fome e na miséria absoluta.

Ocorre que são as prioridades, os princípios defendidos que, em linhas gerais, demonstram tendência de um ou de outro modelo. Essas tendências ou priorizam a saúde, a educação, o bem-estar da população ou priorizam o desenvolvimento financeiro, os lucros, 
as transações comerciais, por exemplo, em detrimento dos direitos, da liberdade, da dignidade, enfim não se priorizam políticas públicas amparadas na ideia de justiça social.

Neste sentido, encontra-se intrínseco o conceito que cada nação tem de desenvolvimento. Para Sen (2000, p. 18):

0 desenvolvimento requer que se removam as principais fontes de privação de liberdade: pobreza e tirania, carência de oportunidades econômicas e destituição social sistemática, negligência dos serviços públicos e intolerância ou interferência excessiva de Estados repressivos. A despeito de aumento sem precedentes na opulência global, o mundo atual nega liberdades elementares a um grande número de pessoas - talvez até mesmo a maioria.

Nessa perspectiva apontada por Amartya Sen, não há desenvolvimento de fato se ele não conduz à liberdade. Sendo assim:

Capacidade e liberdade são sinônimos, uma vez que, para que o individuo possa viver a vida que escolheu, necessita ser livre para essa escolha e precisa ter as possibilidades para vivê-la. Nessa perspectiva, é preciso ser livre para pensar e refletir criticamente, ser livre para argumentar, ser livre para imaginar, pois a liberdade não pode ser um direito a ser reivindicada, ela precisa objetivamente existir. (KOHLS, 2019, p. 176).

Conforme Nussbaum (2012), o desenvolvimento humano de uma nação não pode ser medido ou projetado apenas sobre o Produto Interno Bruto (PIB), mas deve considerar múltiplos enfoques. Levar em consideração as capacidades humanas, a maneira como as pessoas vivem, seu acesso a oportunidades reais de trabalho, saúde e bem-estar são tão importantes quanto os fatores econômicos, de maneira que os direitos fundamentais e inalienáveis dos seres humanos possam existir.

Para a autora,

Quando se pensa em direitos fundamentais, a melhor forma de garanti-los é a de considerálos em termos de capacidades. Entre outros, o direito a participação política, à liberdade religiosa ou à liberdade de expressão, apenas pode ser garantido com maior eficácia se as capacidades para serem exercidos de facto existirem. Ou seja, para que se garante um direito aos cidadãos em qualquer área, é necessário que ele realmente possa ser exercido. Tendo em conta que os direitos são considerados como um fator que é determinante na avaliação da justiça social, só se deveria considerar que uma sociedade é justa quando as capacidades efetivamente tiverem sido realizadas. (NUSSBAUM, 2014, p. 35). 
A educação é, sem dúvida, elemento central nesse debate e as capacidades constituem-se no fundamento que pode direcionar as nações para modelos de desenvolvimento humano. Assim, apresentamos o rol das 10 capacidades que são propostas por Nussbaum (2014), quais sejam:

Quadro 1 - As dez capacidades propostas por Martha Nussbaum

\begin{tabular}{|c|c|}
\hline 1. Vida & $\begin{array}{l}\text { Direito de viver uma vida que não seja interrompida, não morrer prematuramente e/ou } \\
\text { simplesmente viver uma vida sem que esta valha a pena ser vivida. }\end{array}$ \\
\hline 2. Saúde Fisica & $\begin{array}{l}\text { Refere-se à capacidade de viver dignamente com alimentação e moradia adequada, } \\
\text { desfrutando de boa saúde. }\end{array}$ \\
\hline $\begin{array}{l}\text { 3. Integridade } \\
\text { Fisica }\end{array}$ & $\begin{array}{l}\text { Capacidade de poder deslocar-se sem riscos de violência, assaltos, assédio, violência } \\
\text { doméstica, decidir sobre a própria sexualidade e reprodução. }\end{array}$ \\
\hline $\begin{array}{l}\text { 4. Sentimentos, } \\
\text { imaginação e } \\
\text { pensamento }\end{array}$ & $\begin{array}{l}\text { Poder utilizar os sentimentos, imaginar, pensar e argumentar de maneira "autenticamente } \\
\text { humana", considerando uma educação que inclua (mas não limite) a capacidade de ler, } \\
\text { escrever, de perceber e interpretar aquilo que é lido, e ainda a experimentação matemática. } \\
\text { Poder utilizar a imaginação e o pensamento para manifestar-se livremente, ser capaz de } \\
\text { aplicar o próprio pensamento em áreas salvaguardadas pela garantia da liberdade de } \\
\text { expressão como a liberdade política e artística e a prática religiosa. Poder desfrutar de } \\
\text { experiências agradáveis e evitar a dor que não seja benéfica. }\end{array}$ \\
\hline 5. Emoções & $\begin{array}{l}\text { Poder estabelecer ligações afetivas com as coisas e as pessoas de maneira saudável e } \\
\text { livre para sentir todas as emoções. Não estar sujeito à deteriorização do desenvolvimento } \\
\text { emocional devido ao medo e à ansiedade. }\end{array}$ \\
\hline 6. Razão prática & $\begin{array}{l}\text { Poder formar uma concepção do bem e poder dedicar-se à reflexão crítica sobre o } \\
\text { planejamento da própria vida. }\end{array}$ \\
\hline 7. Associação & $\begin{array}{l}\text { Poder viver com e para os outros e poder reconhecer e manifestar preocupação pelos } \\
\text { outros, poder inserir-se socialmente, poder imaginar a situação em que outros se } \\
\text { encontram (a liberdade para reunir-se e discutir as questões politicas). } \\
\text { Ter base de apoio à autoestima e não à humilhação, ser tratado com dignidade e em forma } \\
\text { de igualdade (pressupõe a existência de documentos oficiais de proteção à raça, sexo, } \\
\text { etnia, religião, etc. }\end{array}$ \\
\hline $\begin{array}{l}\text { 8. Outras } \\
\text { espécies }\end{array}$ & $\begin{array}{l}\text { Poder preocupar-se com a sustentabilidade, com animais, plantas, responsabilizando-se } \\
\text { sobre o mundo natural. }\end{array}$ \\
\hline 9. Brincar & Poder rir, divertir-se desfrutar de atividades recreativas. \\
\hline $\begin{array}{l}\text { 10. Domínio } \\
\text { próprio e o } \\
\text { ambiente }\end{array}$ & $\begin{array}{l}\text { Ter capacidade efetiva para participar das decisões políticas, ter direito à participação } \\
\text { política e liberdade de expressão. Poder ter bens imóveis, direito de propriedade, em } \\
\text { igualdade de circunstâncias com outros, poder trabalhar como um ser humano que utiliza a } \\
\text { razão prática e cria uma relação de reconhecimento mútuo com outros trabalhadores. }\end{array}$ \\
\hline
\end{tabular}

Fonte: Nussbaum (2014, p. 42- 44), adaptado por Kohls (2019, p. 178-179). 
Ao analisarmos tais capacidades propostas, percebemos que há uma interligação entre elas e os pressupostos para uma formação que considere um modo de vida democrático e humano, pautado em conceitos de cidadania e justiça social. Dessa forma, entendemos que o fio condutor comum em todas é a dignidade humana.

Além dessas capacidades, Nussbaum (2015) reforça a importância que educação é para "gente" e, antes de podermos planejar um sistema educacional, precisamos entender os problemas que enfrentamos para transformar alunos em cidadãos responsáveis que possam raciocinar e fazer uma escolha adequada a respeito de um grande conjunto de temas de importância nacional e internacional.

Se não insistirmos na importância crucial das humanidades e das artes, elas vão desaparecer gradativamente porque não dão lucro, afirma a autora, visto que elas só fazem o que é muito mais precioso do que isso:

criam um mundo no qual vale a pena viver, pessoas que são capazes de enxergar os outros seres humanos como pessoas completas, com opiniões e sentimentos próprios que merecem respeito e compreensão, e nações que são capazes de superar o medo e a desconfiança em prol de um debate gratificante e sensato. (NUSSBAUM, 2015, p. 143).

Mediante a educação, atitudes já existentes nos sujeitos transformam-se em capacidades internas, ou seja, a educação é um capital para o desenvolvimento do ser humano e, em consequência, para o exercício de outras capacidades (NUSSBAUM, 2012, p. 184). Neste sentido, a educação não é um fim em si mesma, mas um meio para desenvolver capacidades e proporcionar qualidade de vida.

Além disso, segundo a autora, a educação, mesmo que seja básica, dá oportunidades para desfrutar de melhores empregos, interação produtiva com outras pessoas da sociedade, bem como dá melhores possibilidades para participação política. Em médio e longo prazo, também pode corrigir desigualdades sociais. Por isso, garantir acesso, permanência e qualidade na educação é tão importante para o desenvolvimento humano.

Nussbaum defende uma educação ampla para a população, uma formação que não se restringe a competências úteis ao mundo empresarial. É necessário muito mais que isso para que haja desenvolvimento humano. Para ela, saber ler e escrever, por exemplo, dá acesso a algumas oportunidades de trabalho. No entanto, a educação não pode ficar restrita a isso, pois tem uma função social que vai além da ideologia da profissionalização.

A educação precisa pensar em outras habilidades, como por exemplo: "o pensamento crítico, a habilidade de imaginar e de entender a situação de outra pessoa, colocando-a em seu lugar, ou a compreensão de uma das noções elementares sobre a 
história e da atual ordem econômica global." (NUSSBAUM, 2012, p. 184, tradução nossa). Essas habilidades são essenciais para o fomento da cidadania democrática responsável e também para outras capacidades que os sujeitos podem exercer ao longo de suas vidas, inclusive na educação superior.

Para a autora, priorizar as Humanidades nos processos formais de educação é essencial para o desenvolvimento das habilidades anteriormente citadas. Mais do que trabalhar conteúdos considerados úteis para a profissionalização, é importante oportunizar, por meio da educação, condições para que o sujeito tenha consciência de suas atitudes e exerça sua cidadania de maneira lúcida.

A educação superior pode contribuir para esse fim. Além de possibilitar acesso a melhores empregos, ela pode proporcionar uma formação ampla que ofereça condições de participação na sociedade para além de sua profissão. Uma formação para o mundo do trabalho e não para o mercado de trabalho, uma formação humana, com pensamento crítico, que preserve e/ou fortaleça os princípios democráticos e de cidadania.

0 exercício da cidadania consiste em viver de forma digna, não sendo privado dos meios objetivos à sobrevivência: vestir-se, alimentar-se, ter moradia etc., mas também ter condições de desenvolver os aspectos subjetivos da existência: amor próprio, autoconhecimento, autocuidado, equilibrio emocional, desenvolvimento da criatividade, condição para desenvolver pensamento crítico-reflexivo, poder de argumentação, entre outros. Sendo assim, a educação, independente do nível em que se desenvolva, tem papel preponderante na construção dessa subjetividade, a qual pressupõe uma cidadania humanizada, participativa para uma vida que, como assinala Nussbaum (2014): "vale a pena ser vivida."

Neste sentido, Nussbaum (2005) defende um currículo escolar e universitário que supere conteúdos tradicionais que são geralmente trabalhados nas instituições educativas sem um objetivo maior de criticidade e imaginação. A autora cita exemplos de universidades que oferecem, para além desse currículo tradicional, conteúdos que abordam questões culturais, religiosas, artísticas, de gênero, bem como oportunizam que os próprios alunos façam suas escolhas em cursos ou disciplinas que lhes interessam. Em outros exemplos, ela menciona a mudança nas metodologias das aulas ou na organização dos cursos, em uma tentativa de oferecer uma formação mais ampla e diversificada.

Justifica sua posição em prol de uma formação mais humana e ampliada, afirmando que "o cidadão do mundo precisa conhecer a história e seus feitos sociais." (NUSSBAUM, 2005, p. 117, tradução nossa). Ela denomina essa formação de educação multicultural, em que estar aberto para o diálogo, a empatia e respeito com o outro são elementos essenciais nesse processo formativo humano. 
Por isso, ela defende uma aprendizagem que leve em consideração aspectos globais e também locais, valendo-se do contexto e das vivências dos alunos. De acordo com Nussbaum (2012, p. १८5, tradução nossa): "para que uma educação seja boa, deve ser sensivel ao contexto, a história e as circunstâncias culturais e econômicas." Assim, entende o contexto global e local, a fim de proporcionar, por meio da educação, uma visão ampliada do mundo.

\section{CONSIDERAÇÕES FINAIS}

A docência, a ação do professor, sua relação com o conhecimento e com os alunos, têm sido tema permanente de debates nos meios educacionais. Torna-se relevante na perspectiva da busca de alternativas, que, em meio à multiplicidade de situações "novas" que envolvem o processo ensino aprendizagem, possam ser encontrados parâmetros para validar a atuação docente, a relevância de conteúdos, especialmente frente ao avanço tecnológico e à crescente mercantilização da educação, em especial, da educação superior. Optamos por uma formação humanista, tendência assumida por nós em âmbito pessoal e referenciada neste texto, tendo, como base teórica, o pensamento de Marta Nussbaum.

$\mathrm{Na}$ educação superior, temos percebido que as preocupações com relação à docência são essencialmente no tocante às metodologias. Neste sentido, é possível verificar uma verdadeira apologia às ditas metodologias ativas, as quais tratam de elencar dinâmicas de ensino, em sua maioria, oriundas de modelos desenvolvidos em universidades norteamericanas. Nossas preocupações vão além das práticas, métodos e metodologias de ensino, mas na própria essência do que é ensinado, para que e porque é ensinado.

Abordamos o compromisso da educação superior na formação humana e, neste sentido, conforme sugere Martha Nussbaum, uma dessas perspectivas é o ensino que considere as capacidades. Sendo assim, o texto partiu do contexto internacional de crises, questionamentos e dilemas da educação hoje em relação à formação dos sujeitos: uma educação pragmatista para o mercado de trabalho ou uma formação para o desenvolvimento humano?

Concordamos com Nussbaum (2010) quando afirma que essa crise possui enorme gravidade, é mundial, vem sendo gestada há longo tempo, ameaça o futuro da democracia e que, neste aspecto, democracia e educação precisam caminhar juntas para garantirmos uma formação para a cidadania. Por isso, considerando esse cenário, propusemo-nos a discutir os desafios da educação superior no sentido de promover uma formação humana que preserve os princípios democráticos e de cidadania. 
Entendendo a educação como elemento central para o desenvolvimento humano e as capacidades como fundamentos para as nações atingirem esse desenvolvimento, Nussbaum (2012) aponta que há inúmeros desafios para a docência. Dentre esses desafios, podemos citar: planejamento de currículos mais amplos que considerem aspectos globais e locais e que vão além dos conteúdos estritamente relacionados à profissionalização; promoção da dialogicidade e o exercício de empatia e respeito pelas diferentes culturas existentes; implementação de metodologias de ensino e aprendizagem que sejam coerentes com a ideia de formação humana; oferta de condições para que os sujeitos desenvolvam consciência crítica para tomar atitudes lúcidas; fomento do pensamento crítico, para questionar e argumentar com coerência sobre a realidade do mundo atualmente.

Esperamos, diante de um novo cenário, o qual nos encontramos, que novos sentidos e posturas, possam ser reconstruídos, reformulados e repensados e que, a partir dessa pandemia e de todas as dificuldades biopsicossociais em que nos encontramos, em nível mundial, que a nossa esperança em fazer do mundo um lugar melhor prevaleça, que possamos perceber, a partir dessas experiências, que a vida pode ser vivida de maneira mais plena e solidária, somando-se à necessidade de fazer da formação humana um processo mais humanizado e sensivel.

Cabe ressaltar que mantemos a expectativa de que a educação superior direcionese para o compromisso maior com uma formação que, por ser humana e humanizadora, é acima de tudo ética, como afirma Nussbaum (2014, p. 10): "devemos estabelecer o nosso principal compromisso com aquilo que é moralmente bom - e que, por ser bom, pode ser recomendado como tal para todos os seres humanos".

Registramos o propósito que possamos alcançar esse intento de criar essas capacidades e que a docência na Educação Superior se aproprie delas, encontrando mecanismos para fazer o enfrentamento aos modelos de formação de caráter pragmático e mercadológico e que, por meio dela, preservem-se os princípios de humanização, de empatia, de cidadania e democracia.

\section{REFERÊNCIAS}

BARBOSA, M. Educação e cidadania: renovação pedagógica. Amarante: Labirinto, 2006.

BRASIL. Projeto de Lei $n^{\circ}$ 3261/2015. Autoriza o ensino domiciliar na educação básica, formada pela educação infantil, ensino fundamental e ensino médio para os menores de 18 (dezoito) anos, altera dispositivos da Lei $n^{\circ}$ 9.394, de 20 de dezembro de 1996, que estabelece as diretrizes e bases da educação nacional, e da Lei $n^{\circ} 8.069$, de 13 de julho de 1990, que dispõe sobre o Estatuto da Criança e do Adolescente e dá outras providências. Disponivel em: https://www.camara.leg.br/proposicoesWeb/fichadetramitacao?idProposicao=2017117. Acesso em: 24 abr. 2020. 
ESPOSITO, R. Bios: Biopolítica e Filosofia. Tradução de Wagner Melo Miranda. Belo Horizonte: Editora UFMG, 2017.

KOHLS, R. Ensino superior, crise das humanidades e a fragilidade democrática: reflexões a partir do pensamento de Martha Nuussbaum. 2019. Tese (Doutorado em Educação) - Programa de Pós-graduação em Educação, Universidade de Passo Fundo, Passo Fundo, 2019.

MEC cortará verba de universidades que fazem "balbúrdia", diz ministro. GAUCHAZH, 2019. Disponivel em: https://gauchazh.clicrbs.com.br/educacao-e-emprego/noticia/2019/04/mec-cortara-verba-de-universidades-que-fazem-balburdia-diz-ministro-cjv3s3rlu02cs01ro3dkqrf0a.html. Acesso em: 3 jul. 2020.

SANTOS, B. A cruel pedagogia do virus. Portugal: Edições Almedina, abr. 2020.

SOUZA, A. Universidades que promoviam 'balbúrdia', segundo ministro da Educação, tiveram bloqueio abaixo da média. 0 Globo, 2019. Disponível em: https://oglobo.globo.com/sociedade/universidades-que-promoviam-balburdia-segundo-ministro-da-educacao-tiveram-bloqueio-abaixo-da-media-23673349. Acesso em: 3 jul. 2020.

STRIEDER, R. Educação e Humanização: por uma vivência criativa. Florianópolis: Habitus, 2002.

MARCELINO, P. Humanização e sensibilidade: educação e uso do corpo em Giorgio Agamben. 2019. Tese (Doutorado em Educação) - Programa de Pós-graduação em Educação, Universidade de Passo Fundo, Passo Fundo, 2019.

MÜHL, E. Educação e identidade: individuação e individualização na sociedade contemporânea. In: DìZ, A.; SGRÓ, M. (coord.). Teoria crítica de educación y teoria crítica de la sociedade: perspectivas em diálogo. Tandil: Editorial UNICEN, 2018. p. 103-114.

NUSSBAUM, M. Crear Capacidades - Propuestas para el desarrollo humano. Tradução: Albino Santos Mosquera. Españha: Paidós, 2012.

NUSSBAUM, M. Educação e justiça social. Portugal: Edições Pedagogo, 2014.

NUSSBAUM, M. El cultivo de la humanidade: una defensa clásica de la reforma em La educación liberal. Barcelona: Paidós, 2005.

NUSSBAUM, M. Sem Fins Lucrativos - Porque a democracia precisa das Humanidades. Tradução: Fernando Santos. São Paulo: Martins fontes, 2015.

NUSSBAUM, M. Sin fines de lucro: Por qué la democracia necesita de las humanidades. Buenos Aires, Argentina: Katz, 2010.

SEN, A. Desenvolvimento como liberdade. São Paulo: Companhia das Letras, 2000. 
TREVISAN, A. Provocações em torno das novas experiências de formação cultural (Bildung). In: RAJOBAC, R.; BOMBASSARO, L.; GOERGEN, P. (org.). Experiência formativa e reflexão homenagem a Nadja Hermann. Caxias do Sul: Educs, 2016. p. 259-272.

Endereço para correspondência: Rua Morom, 1610, apto 403, Petrópolis, 99051-400, Passo Fundo, Rio Grande do Sul, Brasil; lidianepuiatipagliarin@gmail.com 